to be applicable in $\mathrm{H}_{2} \mathrm{O}_{2}$ decomposition. This feature will be discussed fully in a later communication. A. B. HART

Central Electricity Research Laboratories, Cleeve Road,

Leatherhead, Surrey.

Department of Chemistry,

R. A. Ross

Royal College of Science and Technology, Glasgow, C.I.

${ }^{1}$ Hart, A. B., McFadyen, J., and Ross, R. A. (unpublished work) guère, P. A., and Geoffrion, P., Canad. J. Res., 27, B, 168 (1949). Easton, M. F., Mitchell, A. G., and Wynne-Jones, W. F. K. Trans. Farad.' Soc., 48, 796 (1952).

" Wooten, L. A., and Brown, C., J. Amer. Chem. Soc., 65, 113 (1943). Duncan, J.'F., Trans. Farad. Soc., 45, 879 (1949).

+ Hüttig, G. F., Farad. Soc. Disc., 8, 215 (1950).

"Wells, A. F., Structural Inorganic Chemistry, 381 (Oxford, 1950).

"Forestier, H., C.R. Acad. Sci., Paris, 192, 842 (1931).

\section{End-Point Cryoscopy}

MaNy methods in use for the cryoscopy of solutions suffer from the difficulty of equating an observed freezing point with a definite concentration. The procedure developed by us has avoided this difficulty by determining the temperature of a solution at which the last trace of frozen solvent melts. Thus the freezing point is measured at a concentration which has been established by direct weighing. This is particularly useful for organic solutions where accurate analysis (as for equilibrium cryoscopy) is often impractical.

\begin{tabular}{lccc}
\multicolumn{3}{c}{ Table 1 } \\
Substance & $\begin{array}{c}\text { Molecular } \\
\text { weight }\end{array}$ & $\begin{array}{c}\text { Slope of concentration } \\
\text { v. melting point }\end{array}$ & $\begin{array}{c}\text { Slope } \times \text { mole- } \\
\text { cular weight }\end{array}$ \\
Naphthalene & 128 & 225 & 288 \\
Benzoic acid & 122 & 227 & 277 \\
Nitrobenzene & 123 & 225 & 277 \\
Benzil & 210 & 135 & 273 \\
Methyl salicylate & 152 & 187 & 284
\end{tabular}

About $5 \mathrm{ml}$. of solution is shaken in a small glass bulb after cooling sufficiently to produce a small amount of frozen solvent. The temperature, measured by a thermistor inside the bulb, is plotted against time; this is most conveniently achieved with a recording amplifier. The temperature remains steady for a while, then increases regularly and slowly while any frozen solvent remains, but the slope changes sharply as the last trace of solid melts. The intersection of the two linear portions is a measure of the

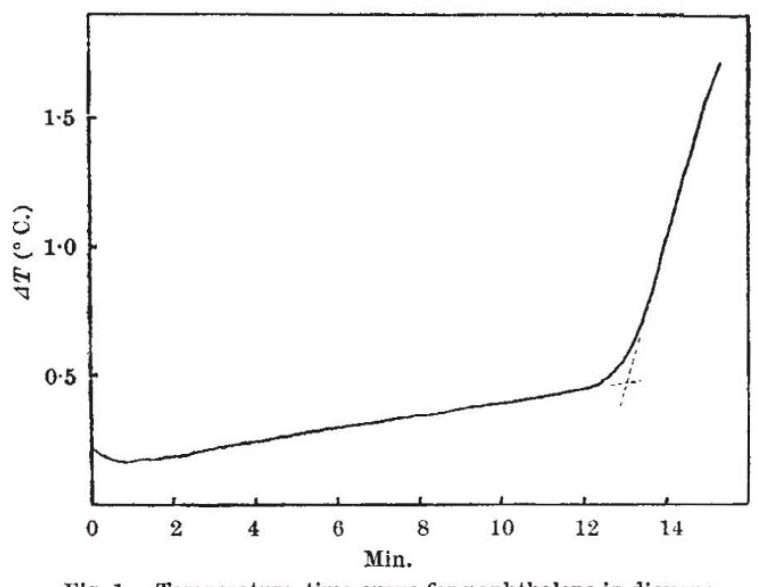

Fig. 1. Temperature-time curve for naphthalene in dioxane required melting point. A typical curve is shown in Fig. 1. Each determination requires about $10 \mathrm{~min}$.

The results given in Table 1 were obtained for dioxane solutions, 4-5 measurements being made for each substance.

\section{R. F. GREenwood}

$$
\text { C. Heitler }
$$

Department of Applied Chemistry, Northampton College of Advanced Technology, London, E.C.1.

\section{Adsorption of Long-Chain Aliphatic Amines on Glass Vessels}

Work involving the use of aliphatic amines in aqueous solutions is usually carried out in glass apparatus. We have found that in the case of $n$-dodecylamine a significant decrease in the concentration occurs at $p \mathrm{H}$ values greater than 7 due to adsorption of the amine at the glass-water interface. A larger decrease occurs if a plastic, such as polyethylene, is in contact with the solution.

Fig. 1 presents data obtained using $250 \mathrm{ml}$. of $n$-dodecylamine solution in a spherical glass vessel. Concentration loss is plotted against the final solution concentration after contact with the vessel for 15 min. Results obtained using a polythene beaker and an oxide-coated nickel crucible are given for comparison, the volume of amine solution used in the latter case being $50 \mathrm{ml}$.

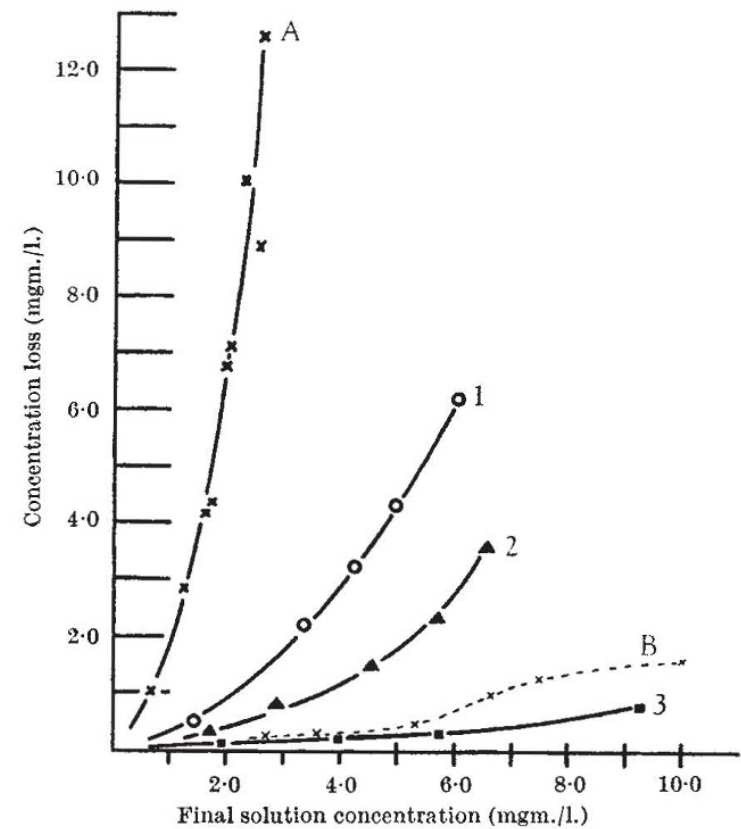

Fig. 1. Loss of $n$-dodecylamine from aqueous solutions of differing final concentrations in: (1) glass at $p \mathrm{H} \quad 9 \cdot 5 ;(2)$ glass at $p \mathrm{H}$ coated nickel at $p \mathrm{H} 7 \cdot 0$; (A) polythene at $p \mathrm{H} 9.5 ;(B)$ oxideconcentration loss + final solution concentration)

If the surface of the glass was smooth, the area in contact with the solution was $160 \mathrm{~cm} .^{2}$. Assuming close packing of the amine molecules and an area of $20.5 \AA .^{2}$ per molecule, the quantity of amine required to give a complete monolayer was $2.4 \times 10^{-5} \mathrm{gm}$. The loss to the vessel was very much larger than this, so multi-layers must have been formed. This is in agreement with results obtained for the adsorption of 